\title{
Midday reversal of equatorial ionospheric electric field
}

\author{
R. G. Rastogi \\ INSA Senior Scientist, Department of Physics and Space Sciences, Gujarat University, Ahmedabad 380 009, India
}

Received: 7 June 1996 / Revised: 27 March 1997 / Accepted: 1 April 1997

\begin{abstract}
A comparative study of the geomagnetic and ionospheric data at equatorial and low-latitude stations in India over the 20 year period 1956-1975 is described. The reversal of the electric field in the ionosphere over the magnetic equator during the midday hours indicated by the disappearance of the equatorial sporadic E region echoes on the ionograms is a rare phenomenon occurring on about $1 \%$ of time. Most of these events are associated with geomagnetically active periods. By comparing the simultaneous geomagnetic $H$ field at Kodaikanal and at Alibag during the geomagnetic storms it is shown that ring current decreases are observed at both stations. However, an additional westward electric field is superimposed in the ionosphere during the main phase of the storm which can be strong enough to temporarily reverse the normally eastward electric field in the dayside ionosphere. It is suggested that these electric fields associated with the $V \times B z$ electric fields originate at the magnetopause due to the interaction of the solar wind and the interplanetary magnetic field.
\end{abstract}

\section{Introduction}

The establishment of geomagnetic and ionospheric observatories at low magnetic latitudes in Peru and Columbia during IGY-IGC period have provided very valuable data on the equatorial electrojet and equatorial ionosphere. Knecht and McDuffie (1962) have described the special properties of the equatorial sporadic E layer, $E_{s}-q$, which was shown to be closely related to the equatorial electrojet both in daily and latitudinal variations.

Bartels and Johnston (1970a, b) had shown that the geomagnetic horizontal field, $H$, at Huancayo during the daytime hours on certain occasions decrease below the corresponding nighttime base value. Gouin and Mayaud
(1967) called such events counter electrojets and suggested they may be due to a westward current in the equatorial ionosphere. Rastogi et al. (1971) showed, for the first time, that the counter electrojet events observed in geomagnetic $H$ field, the absence of $E_{s}-q$ reflections in the ionograms and the reversal of the ionospheric drift direction during the daytime hours at an equatorial station were concurrent phenomena. Fambitakoye et al. (1973) showed that the reversal of the latitudinal profiles of $\Delta H$ and $\Delta Z$ are the main criterions for the disappearance of $E_{s}-q$ rather than the decrease $\Delta H$ below its night time level at the equatorial station. Comparing the high resolution modified range time intensity (MRTI) records of VHF backscatter radar echoes at Jicamarca and the magnetograms at Huancayo and Fuquene, Rastogi et al. (1977) showed that the E region irregularities disappear precisely (with an accuracy of less than 2 min) when $\Delta H$ at Huancayo minus $\Delta H$ at Fuquene decreases below the corresponding night time value. Similar results were obtained by Rastogi and Patil (1986) by comparing Doppler shift data of VHF backscatter radar echoes at Thumba and $\Delta H$ at Kodaikanal minus $\Delta H$ at Alibag.

Rastogi (1974a) described the first global morphology of the occurrence of counter electrojet based on the visual examination of the magnetograms of a number of equatorial stations. The counter electrojets are observed mostly either in the morning hours around $0700 \mathrm{LT}$ or during the afternoon hours around 1600 LT. Very few events were observed around noon hours. The occurrence of counter electrojet events are inversely related to the sunspot activity. During geomagnetic disturbed periods, the presence of counter electrojet events cannot be precisely estimated by simple visual examination of the ionograms.

Rastogi (1975) suggested that the observed daily variation of the $H$ field at an equatorial station is due to the superimposition of the global $S q$ current flowing eastward at $106 \mathrm{~km}$ and the electrojet current flowing either eastward or westward at $100 \mathrm{~km}$ altitude. Alex et al. (1986) have discussed the two prominent sources 
of westward electrojet current, one due to certain abnormal modes of luni-solar semi-diurnal tides, and another due to the interaction of solar plasma on the sunward side of the magnetosphere. Thus, the westward current has to exceed the global eastward $S q$ current at that time to generate counter electrojet event. Since the $S q$ current maximizes around 1100-1200 LT, the occurrence of the counter electrojet should be least probable around noon hours. The partial counter electrojet cannot be identified by visual examination of the magnetograms and one has to compare $\Delta H$ at an equatorial and another low-latitude station along the same longitude before deriving the index of counter electrojet. The ionograms depict the conditions of the region of the ionosphere from where the radio waves are reflected or scattered back. Thus, the disappearance of the equatorial type of sporadic $E$ reflections on equatorial ionograms would be a more reliable and sensitive index of the counter electrojet events.

Rastogi (1974b) has described the characteristics of the sporadic $E$ layer at Kodaikanal. It was shown that the time of the first disappearance of the $E_{s}-q$ in the morning varied from day to day depending upon growth of the normal electrojet. Similarly the occurrence of $E_{s}-q$ in the evening hours was greatly affected by the counter electrojet. However during the midday hours, $E_{s}-q$ had occurred over $90-99 \%$ of times. Rastogi (1972a) had shown that during a geomagnetic storm, $E_{s}-q$ at an equatorial station does not indicate any decrease of the maximum $E_{s}-q$ frequency, but it does disappear completely during very large decreases of $\Delta H$ at the particular station.

\section{Data}

The ionospheric observatory at Kodaikanal in India has been in continuous operation since September 1952 and has regularly published its ionospheric data. It was decided to study the counter electrojet in Indian longitudes using the data of the absence of $E_{s}-q$ at Kodaikanal. The period of study chosen was January 1956 to December 1975 which covered the period of maximum $($ sunspots $=200)$ to minimum $($ sunspots $=0)$ solar activity. The list of stations whose data is used, with their coordinates, is given in Table 1.

The whole data covering a period of twenty years were divided into two groups: (1) 10 years of high sunspots activity consisting of years 1956 to 1961 and 1968 to 1971; (2) 10 years of low sunspots activity consisting of the years 1962-1967 and 1972-1975. The data for each epoch were further grouped into the following Lloyd seasons: (1) D-months consisting of November, December, January and February representing local winter season; (2) E-months consisting of March, April, September and October; and (3) J-months consisting of May and June, July and August months representing local summer season.

\section{Results of the analysis}

Figure 1 shows the percent occurrence of the disappearance of $E s q$, referred to as $N o-E_{s}-q$ events, for each of the seasons of high and low sunspot epochs. Referring to annual average curves, there is some shift in the curve towards higher local time during high sunspot years suggesting that the forenoon $N o-E_{s}-q$ events are more common during the high sunspot than during the low sunspot years and the case is reversed for afternoon $N o-E_{s}-q$ events. The same trend is seen for any individual season. This is in conformity with the results of Patil et al. $(1991 \mathrm{a}, \mathrm{b})$ that the counter electrojet events in the Indian sector were seen more often in the afternoon than in the forenoon hours during 1964-65 but the events were more often secn in the forenoon hours of high sunspot years of $1958-59$. It is to be noted that the $\mathrm{No}-E_{s}-q$ events were least frequent (about $1-2 \%$ of time) around $1100 \mathrm{LT}$ which happens to be the time of the peak electrojet current during the day. Regarding the seasonal effects, $N o-E_{s}-q$ events during midday hours were most frequent during D-months at about $3 \%$ and least frequent during E-months being only $0.3-0.5 \%$ of time. It is to be noted that the peak altitude of the electrojet in the Indian sector is weakest during Dmonths and strongest during $\mathrm{E}$ months (Rastogi and Patil 1992).

Figure 2 a shows the year to year variation of the total number of days with $N o-E_{s}-q$ events at Kodaikanal during any of the hours 1000-1200 LT. In Fig. 2b are shown the number of $N o-E_{s}-q$ events at $1100 \mathrm{LT}$ during different months of the year. Referring to Fig. 2a, no apparent solar cycle variation of $N o-E_{s}-q$ events can be derived. It may be noted that the occurrence of afternoon counter electrojet events are inversely related to the sunspot numbers (Rastogi, 1974a) while the midday counter electrojet, observed less frequently, does not show any clear dependence on sunspot numbers.

Referring to Fig. 2b, No- $E_{s}-q$ events occur most frequently during D-months and least frequently during E-months with a secondary peak during J-months. A total of 96 events were observed at 1100 LT during the
Table 1. List of stations whose data is utilized in the present study

\begin{tabular}{|c|c|c|c|c|c|}
\hline \multirow[t]{2}{*}{ Station } & \multirow[t]{2}{*}{ Code } & \multicolumn{2}{|l|}{ Geographic } & \multirow{2}{*}{$\frac{\text { Dipole }}{\text { Latitude }}$} & \multirow{2}{*}{$\begin{array}{l}\text { Dip } \\
\text { Latitude }\end{array}$} \\
\hline & & Latitudes ${ }^{\circ} \mathrm{E}$ & Longitude ${ }^{\circ} \mathrm{N}$ & & \\
\hline Trivandrum & TRD & 8.5 & 77.0 & $1.1^{\circ} \mathrm{S}$ & $0.6^{\circ} \mathrm{S}$ \\
\hline Kodaikanal & KOD & 10.2 & 77.5 & $0.6^{\circ} \mathrm{N}$ & $1.5^{\circ} \mathrm{N}$ \\
\hline Annamalainagar & ANN & 11.6 & 79.7 & $1.4^{\circ} \mathrm{N}$ & $2.5^{\circ} \mathrm{N}$ \\
\hline Alibag & $\mathrm{ABG}$ & 18.4 & 72.5 & $9.5^{\circ} \mathrm{N}$ & $12.0^{\circ} \mathrm{N}$ \\
\hline
\end{tabular}




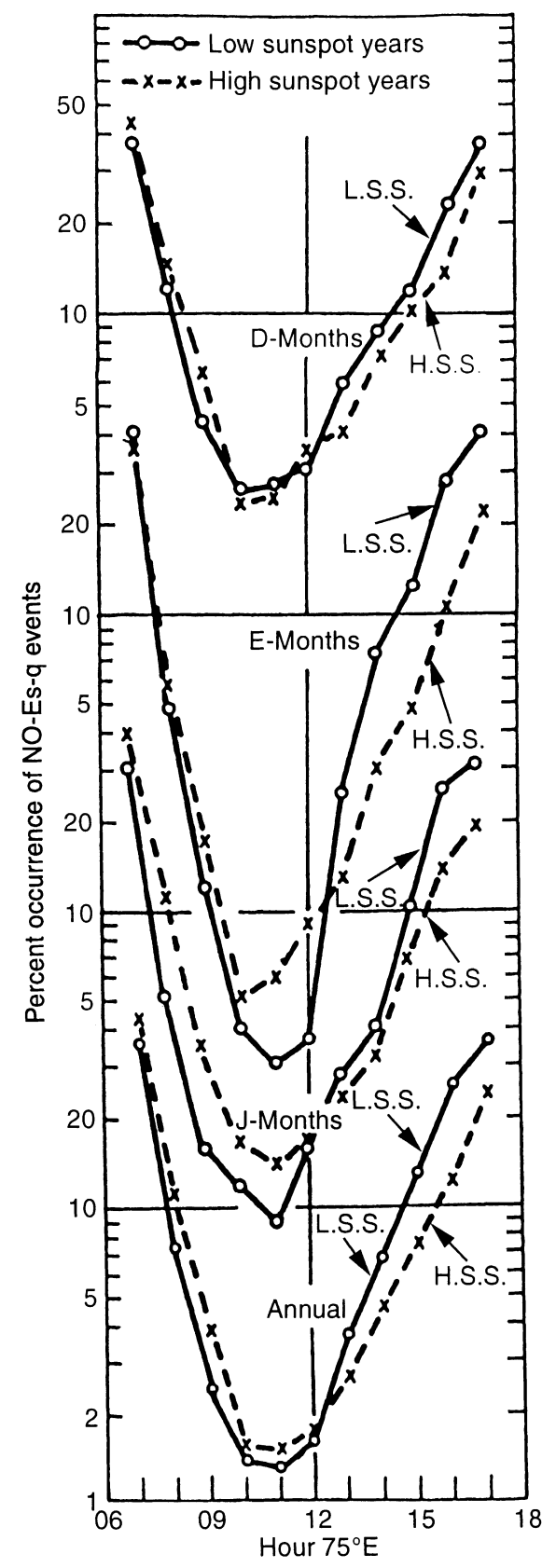

Fig. 1. Daily variation of $N o-E_{s}-q$ events at Kodaikanal averaged for the D, E and J-months of low and high sunspot years

20 year period of $1956-75$, out of which 23 events were observed in January, 6 in June and only 2 in March.

Next we examined the geomagnetic disturbance index on the days when $E_{s}-q$ were absent at any hour between 1000-1200 LT. Figure 3 shows the percent occurrence of $N o-E_{s}-q$ events as a function of daily sum $\mathrm{Kp}$ index $(\Sigma \mathrm{Kp})$ for low and high sunspot years. During high sunspot years, the $\Sigma \mathrm{Kp}$ were high during $N o-E_{s}-q$ days. The peak of the histogram shows a value around 30 for $\Sigma \mathrm{Kp}$. Out of 101 events during the ten year period, 59 events were observed during the main phase of a geomagnetic storm. Extremely few cases were observed during undisturbed days. During low sunspots, out of 79

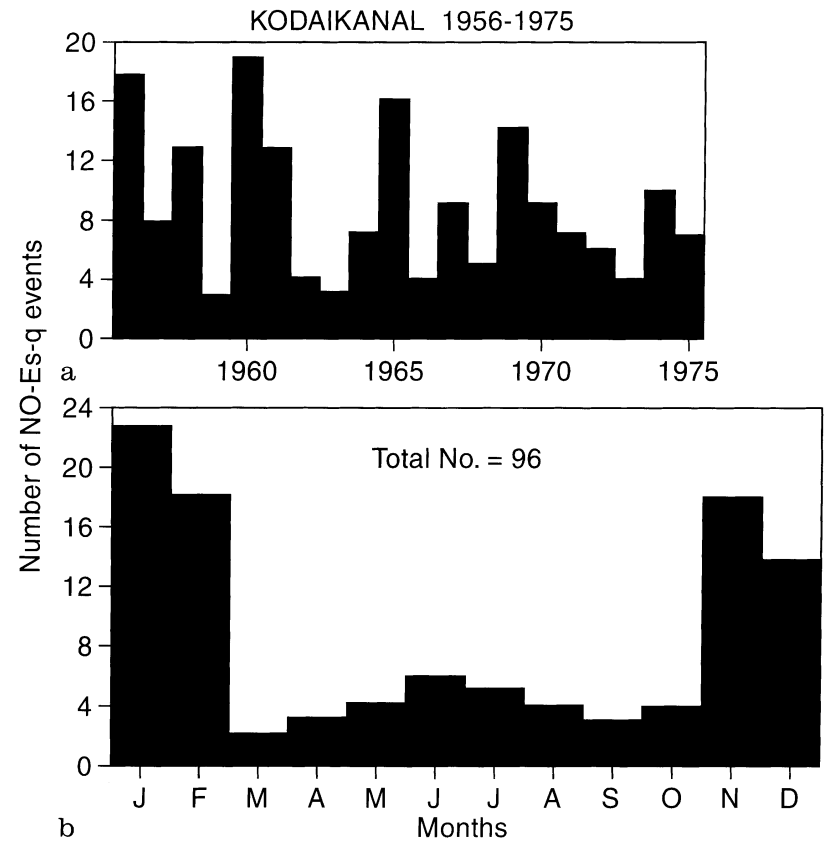

Fig. 2. a Year to year variations of $N o-E_{s}-q$ events at Kodaikanal during the interval of 1000-1200 LT; 2 b month to month variation of the total number of $N o-E_{s}-q$ events at Kodaikanal averaged for the period of study 1956-75

events, the storm was in progress on 22 days. Some of the events were observed on the days immediately following the storm. Of course, during the low sunspot years a significant number of cases of $N o-E_{s}-q$ was observed on very quiet days when the normal electrojet intensity was very small. Such quiet time $N o-E_{s}-q$ events were fairly common during the years 1964,1965 . We are not combining here the midday occurrence of $N o-E_{s}-q$ with afternoon counter electrojet occurring between 1400 and 1800 hours. Thus, it may be concluded that the reversal of electrojet current during the noon hour is basically a disturbed-day phenomenon.

The geomagnetic data were next examined during the storms when $E_{s}-q$ was observed to be absent during the midday hours. During normal eastward electrojet current conditions a pronounced peak of $\Delta H$ is observed at Trivandrum. The deviation of the geomagnetic vertical field $Z$ from its midnight value would be practically zero near the center of the electrojet. At Annamalainagar (ANN) which lies near the northern fringe of the electrojet, $\Delta Z$ would experience the largest negative deviation. During a counter electrojet event, identified by a negative value of $\Delta H$ (TRD-ABG) or of $\Delta H$ (KOD-ABG), the deviation of vertical field $Z$ would be positive at ANN and KOD.

The first $N o-E_{s}-q$ event around noon hours occurred on 4 March 1964. A gradual commencement type of storm was observed at Kodaikanal at $1818 \mathrm{~h}$ on 3 March 1964 and the storm range in $H$ field was $162 \mathrm{nT}$. Figure $4 \mathrm{a}$ shows the variations of the Dst $(H)$ index, disturbance daily variations of $\Delta H$ at $\mathrm{ABG}$ and KOD, $\Delta Z$ (KOD-ABG) and the maximum $E_{s}-q$ frequency at 3 , 4 and 5 March 1964. It is seen that the Dst $(H)$ at Alibag 


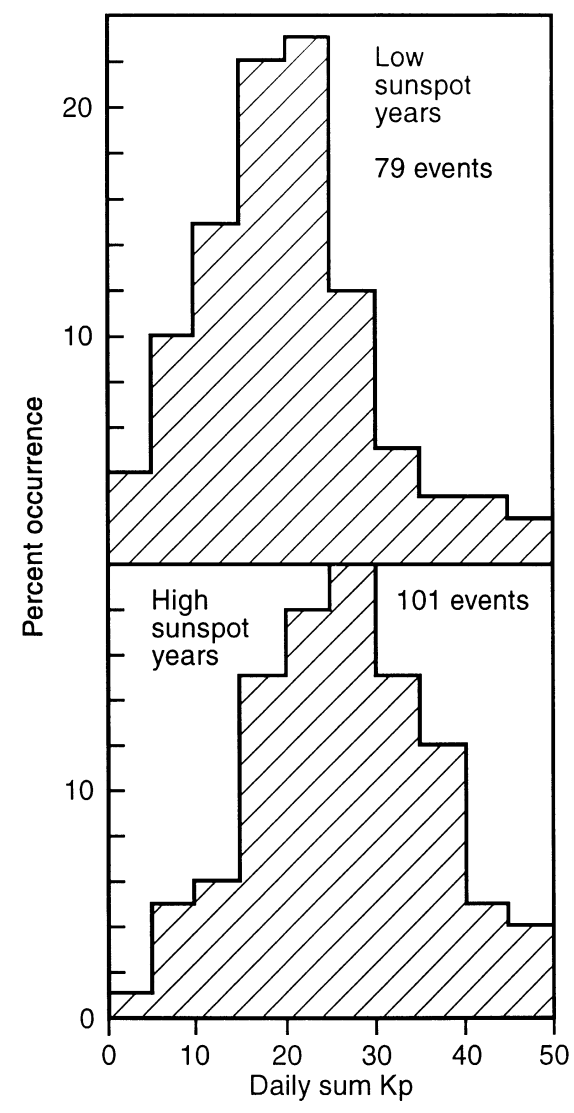

Fig. 3. Distribution of daily sum Kp index ( $\Sigma \mathrm{kp})$ on days of $N o-E_{s}-q$ event during midday hours for low and high sunspot years

varied with time in a similar fashion as the international equatorial Dst $(H)$ index, but the $D s t(H)$ at Kodaikanal showed larger fluctuations with deep decreases of the $H$ field around 1200 and $1700 \mathrm{~h}$ on 4 March 1964. The large decrease $H$ at KOD around $1200 \mathrm{~h}$ was associated with a positive peak at $\Delta Z$ at KOD and a negative peak of $\Delta H$ (KOD-ABG). The ionograms at Kodaikanal on 4 March 1964 showed clear $E_{s}-q$ reflections at $1015 \mathrm{~h}$ and its sudden disappearance at $1030 \mathrm{~h}$ (Fig. 4b). The $E_{s}-q$ echoes were absent at Kodaikanal till $1130 \mathrm{~h}$. Thus, the $E_{s}-q$ at Kadaikanal had disappeared only when $\Delta H$ (KOD-ABG) was negative and $\Delta Z$ (KOD) positive, suggesting a westward (counter) electrojet current at that time.

The second $N o-E_{s}-q$ event discussed refers to the SC type of geomagnetic storm which had started at $0008 \mathrm{~h}$ $75^{\circ}$ E on 1 December 1960 . Figure 5 shows the variations of various parameters of magnetic and $E_{s}-q$ data for the period 30 November to 2 December 1960. Based on the variation of the $D s t$ index, the main phase had started on 1 December 1960 at 0500 hours, reached its largest depression of about $-130 \mathrm{nT}$ at $1700 \mathrm{~h}$ and at $2300 \mathrm{~h}$ and started recovering thereafter. The midday depression of $\Delta H$ was $-65 \mathrm{nT}$ at $\mathrm{ABG},-200 \mathrm{nT}$ at KOD and at TRD, thereby $\Delta H$ (TRD-ABG) or $\Delta H$ (KOD-ABG)
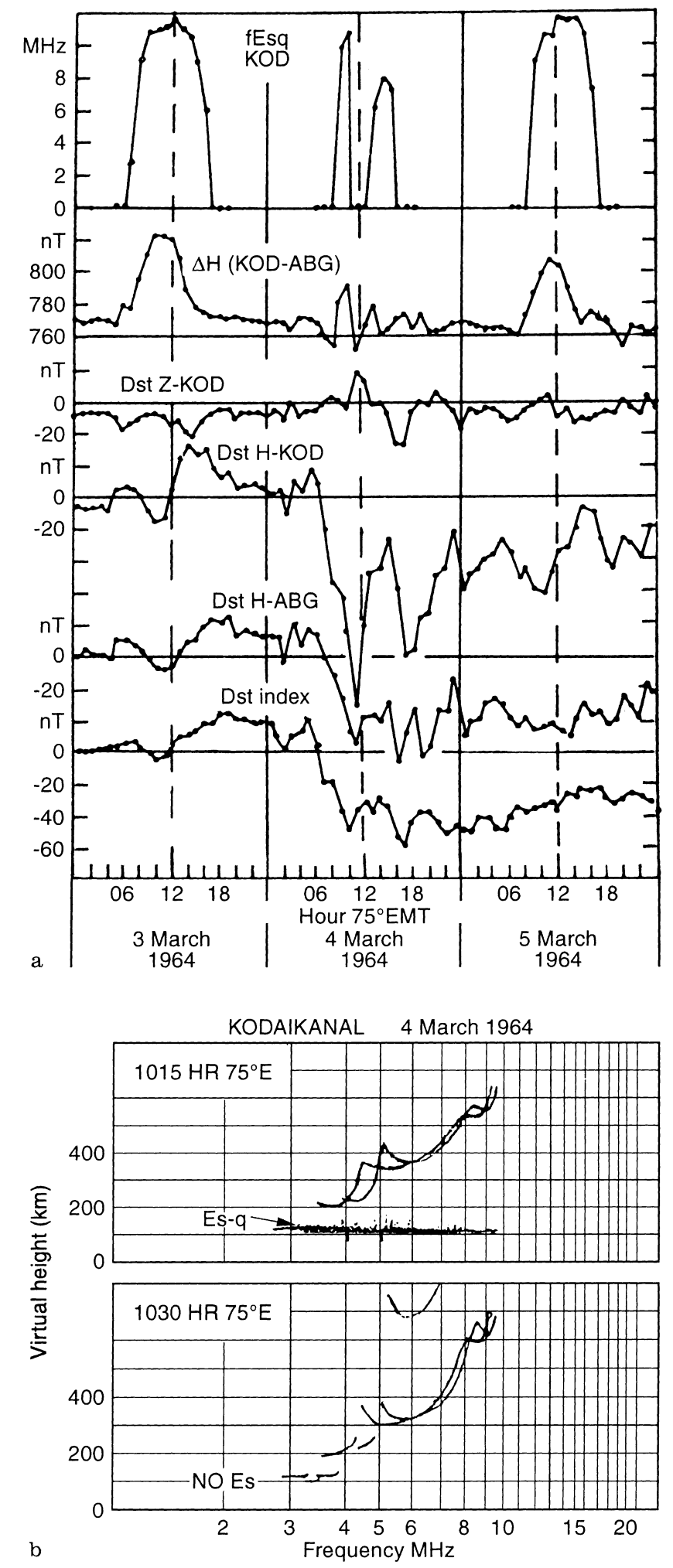

Fig. 4. The storm time variations of $D s t$ index, $\Delta H$ at $\mathrm{ABG}$ and KOD, $\Delta Z$ at $\mathrm{KOD}, \Delta H$ (KOD-ABG) and the maximum frequency reflected from the ionosphere $(f E s q)$ over Kodaikanal during the GC type geomagnetic storm starting at $1820 \mathrm{~h}$ on 3 March 1964; b ionograms at Kodaikanal on 4 March 1964 showing the presence of $E_{s}$ - $q$ echoes at $1015 \mathrm{~h}, 75^{\circ} \mathrm{E}$ and complete absence of $E_{s}-q$ echoes at $1030 \mathrm{~h}$ 


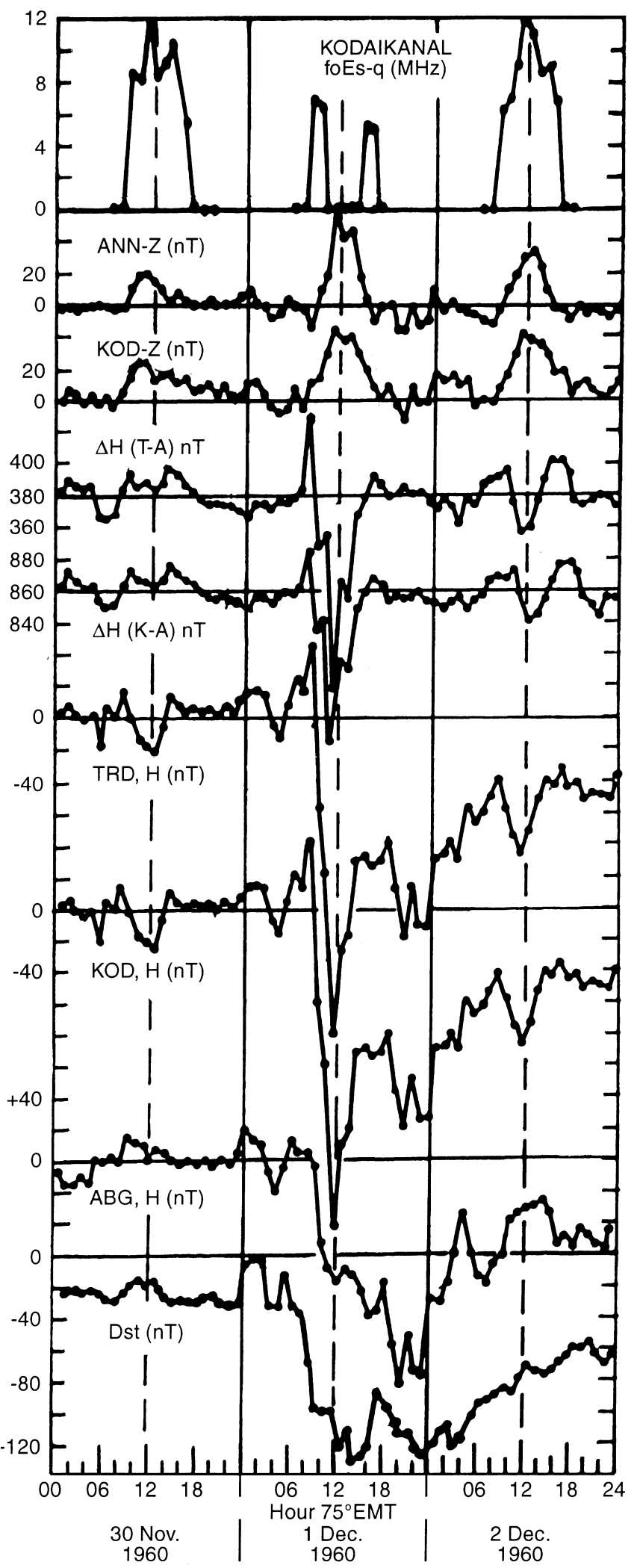

Fig. 5. The storm time variations of $D s t$ index, $H$ fields at $A B G$, $\mathrm{KOD}, \mathrm{TRD}, \Delta H(\mathrm{~K}-\mathrm{A}), \Delta H$ (T-A), KOD $Z$, ANN $Z$ and $f \mathrm{O} E s q$ at Kodaikanal during the sudden commencement storm starting at $75^{\circ} \mathrm{h}$ EMT on 1 December 1960 showed a very large decrease around $1100 \mathrm{~h}$. The value of $\Delta Z$ at KOD or at ANN was strongly positive. These feature suggest the existence of a strong counter electrojet around midday hours on 1 December 1960, further confirmed by the absence of $E_{s}-q 1100-1400 \mathrm{~h}$. It should be noted that a large decrease of $D s t$ during the late evening hours on 1 December 1960 was associated with almost similar decreases of $\Delta H$ at ABG, KOD and

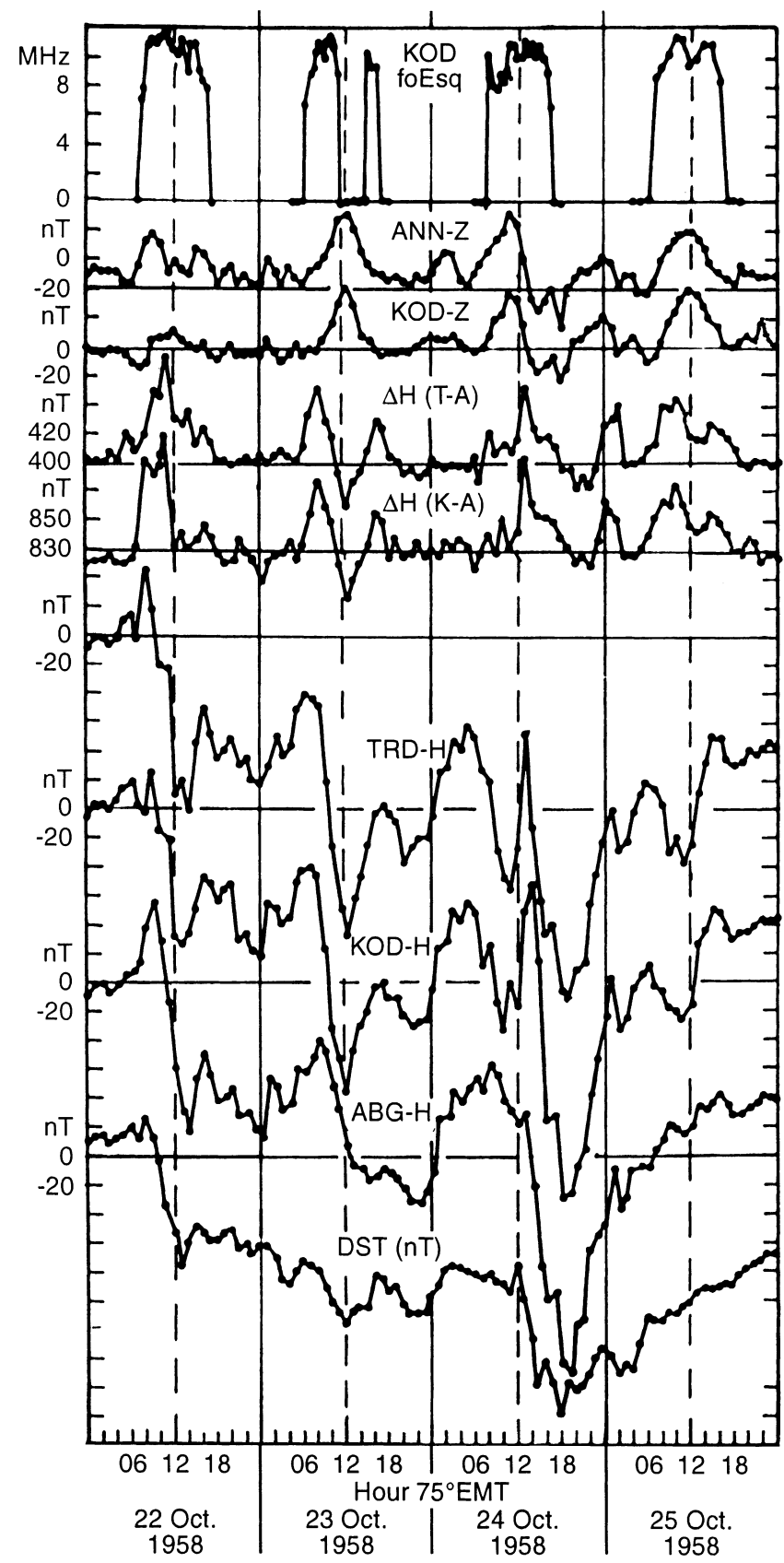

Fig. 6. The storm time variation of $D s t$ index, $H$ fields at $A B G$, KOD, TRD, $\Delta H$ (T-A), KOD-Z, ANN- $Z$ and $f \mathrm{O} E s$ at Kodaikanal during sudden commencement storm starting at $0214 \mathrm{~h} 75^{\circ} \mathrm{E}$ on 22 October 1958 
ABG and did not show any evidence of a counter electrojet at that time.

The next event discussed refers to the SC storms starting at $0214 \mathrm{~h} 75^{\circ} \mathrm{E}$ on 22 October 1958, which was followed by another storm at $1218 \mathrm{~h} 75^{\circ} \mathrm{E}$ on 24 October 1958. Figure 6 shows the storm time variations of the various parameters for the period 22 to 25 October 1958. This period showed major depressions of storm time $H$ field at ABG with a magnitude of $-100 \mathrm{nT}$ at $1400 \mathrm{~h}$ on 22 October, another of $-150 \mathrm{nT}$ at $2200 \mathrm{~h}$ on 23 October and the third one of $-200 \mathrm{nT}$ at $1900 \mathrm{~h}$ on 24 October 1958. The first depression on 22 October was associated with similar depressions at KOD and TRD and no counter electrojet effects were observed. The second depression on 23 October around midday hours was associated with much larger depressions at KOD and TRD of magnitudes about $-200 \mathrm{nT}$ which produced a large decrease of $\Delta H$ (TRD-ABG) and in $\Delta H$ (KOD-ABG) and a major positive peak of $\Delta Z$ at KOD and ANN resulting in the disappearance of the $E_{s}-q$ at Kodaikanal. The third depression, although the largest one, was associated with similar magnitudes of $\Delta H \approx-250 \mathrm{NT}$ at all the Indian stations and did not produce any changes in the sporadic e layer at Kodaikanal.

Thus, it can be concluded that some large geomagnetic storms during its main phase produce an abnormally large depression of $\Delta H$ at the stations close to the magnetic equator and in the local noon meridian. These depressions at the equator of $\Delta H$ are much larger than the corresponding depression of $\Delta H$ at mid latitudes or the corresponding Dst index.

\section{Discussion}

The analyses of single station geomagnetic data have been hampered by the difficulties of isolating the ionospheric and magnetospheric sources of the changes of geomagnetic field components observed at ground level. The simultaneous observations of the geomagnetic field and the ionospheric electric field through VHF backscatter radar would isolate the two sources of the disturbance electric currents. However the scarcity of radar facilities at low latitudes and the few radar available from Jicarmaca data makes this combination impracticable. It had been shown that the unique combination of the network of geomagnetic and ionospheric observatories in India and the easy availability of these data make it a very useful source of studying magnetospheric and ionospheric interactions.

Rastogi (1972b) had shown the effect of geomagnetic storm of $f$ Es at equatorial latitudes has been not to decrease the value of $f$ oEs, but to inhibit the occurrence of $E_{s}-q$ at certain moments when a large depression of the $H$ field is observed at the station. Rastogi and Patel (1975) were first to show that during a compressed state of the magnetosphere as a result of intense plasma bubble from the Sun, a sudden change of the component of the interplanetary magnetic field $\mathrm{Bz}$ from southward to northward produces a $-V \times \mathrm{Bz}$ electric field at the magnetopause which when imposed on the ionosphere caused a reversal or decrease of equatorial ionospheric electric field evidenced by the Doppler shift of equatorial VHF backscatter radar echoes or with the disappearance of sporadic echoes from the equatorial $\mathrm{E}$ region of the ionosphere by an ionosonde. These Es echoes were shown to be the scattered reflections of HF and VHF radio waves from the cross field instabilities generated at $100 \mathrm{~km}$ level due to the interaction of vertically upward Hall polarization field with the vertical gradient of the electron density (Rastogi, 1972b). Any reversal of horizontal electric field at $100 \mathrm{~km}$ altitude in the equatorial ionosphere would reverse the direction of the Hall polarization field, inhibiting the cross-field irregularities in less than one minute. Kikuchi et al. (1978) and Kikuchi and Araki (1979) have shown that the electric field imposed on the polar latitudes originating from the magnetopause can be instantly transmitted to equatorial latitudes through the zeroth order transverse magnetic (TMo) waveguide mode by the Earth-ionosphere waveguide system.

Rastogi (1973) has described the data from the ionosonde at Huancayo and VHF back-scatter radar at Jicamarca during the major geomagnetic storm of 7-9 March 1970. The storm was associated with large depressions of the $H$ field at Huancayo during the daytime hours on these days. These decreases of $\Delta H$ were found to be remarkably simultaneous with the disappearance of $E_{s}-q$ echoes on the ionograms and with the downward reversal of the vertical $F$ region electron drifts. These observations confirmed that the absence of $E_{s}-q$ during geomagnetic storms are due to the temporary superimposition of westward electric field over the equatorial ionosphere.

The main phase of the storm besides the gradual decrease of the $H$ field at low latitudes is marked with the number of substorms associated with the passages of solar wind discontinuities. The fluctuations of the $B z$ component of IMF during these substorms have very different effects on the $H$ field at equatorial and other low latitudes. Rastogi (1977) had shown that during the geomagnetic storm of 16 October 1970, a sudden change of the latitude $\theta$ of IMF form $-90^{\circ}$ to $+90^{\circ}$ at 1900 UT was associated with a decrease of $H$ field at Huancayo by more than $200 \mathrm{nT}$ but no change was observed in $H$ at low-latitude Fuquene or in the equatorial $D s t$ index.

The present analyses clearly shows that the storm time variation of the geomagnetic field at an equatorial station has two components, one due to the equatorial ring current and another due to changes of the electric field of magnetospheric origin penetrating from high latitudes.

A coordinated study of all three components of the geomagnetic field at geomagnetic observatories in the Indo-Russian sector together with various magnetosphere and interplanetary data would lead to new insight into the low-latitude geomagnetic storm phenomena.

Acknowledgements. The author thanks the Indian National Science Academy, New Delhi for offering him the Senior Scientist's 
position, and the Department of Physics, Gujarat University Ahmedabad and Physical Research Laboratory, Ahmedabad for providing the facilities for this research. The author also thanks the referee whose remarks have improved the presentation of the paper. The final version of the paper was prepared during the author's visit to the School of Physics, La Trobe University, Bundoora, Australia 3083.

Topical Editor D. Alcaydé thanks B. Reinisch for his help in evaluating this paper.

\section{References}

Alex, S., A. Patil, and R. G. Rastogi, Equatorial counter electrojet solution of some delimas, Ind. J. Radio Space Phys., 15, 114118, 1986.

Bartels, J., and H. F. Johnston, Geomagnetic tides in horizontal intensity at Huancayo: 1, J. Geophys. Res. 75, 269-308, 1970a.

Bartels, J., and H. F. Johnston, Geomagnetic tides in horizontal intensity at Huancayo: 2, J. Geophys. Res., 75, 485-592, 1970 b.

Fambitakoye, O., R. G, Rastogi, J. Tabbagh, and P. Vila, Counter electrojet and Esq disappearance, J. Atmos. Terr. Phys., 35, 119-1126, 1973.

Gouin, P., and P. N. Mayaud, A propos de l'existence possible d'un contre-electrojet aux latitudes magétiques équatoriales, Ann. Geophysicae, 23, 41-47, 1967.

Knecht, R. W., and R. E. McDuffie, On the width of the equatorial Es belt, in: Ionospheric Sporadic E, Ed. E.K. Smith, and S. Matsushita, Pergamon, Press, Oxford, pp. 215-218, 1962.

Kikuchi, T., and T. Araki, Horizontal transmission of the polar electric field to the equator, J. Atmos. Terr. Phys., 41, 927-936, 1979.

Kikuchi, T., T. Araki, H. Maeda, and K. Mackawa, Transmission of polar electric field to the equator, Nature, 273, 650-651, 1978.
Patil, A. R., D. R. K. Rao, and R. G. Rastogi, Equatorial electrojet strengths in the Indian and American sectors, Part I: during low solar activity, J. Geomagn. Geoelectr., 42, 801-811, 1990a.

Patil, A. R., D. R. K. Rao, and R. G. Rastogi, Equatorial electrojet strengths in the Indian and American sectors, Part II: during low solar activity. J. Geomagn. Geoelectr., 42, 813-823, 1990b.

Rastogi, R. G., Equatorial sporadic E layer during geomagnetic storms, J. Geomagn. Geoelect., 24, 429-440, 1972a.

Rastogi, R. G., Equatorial sporadic E and plasma instabilities, Nature, 237, 73-75, 1972b.

Rastogi, R. G., Esq layer on Huancayo during March 1970 geomagnetic storm, Planet. Space Sci., 21, 197-203, 1973.

Rastogi, R. G., Westward equatorial electrojet during day-time hours, J. Geophys, Res., 79, 1503-1512, 1974a.

Rastogi, R. G., Some remarks on the equatorial sporadic E layer at Kodaikanal, Proc. Ind. Acad. Sci., 20, 257-267, $1974 b$.

Rastogi, R. G., On the simultaneous existence of eastward and westward flowing electrojet current, Proc. Ind. Acad. Sci., 81, 80-92, 1975.

Rastogi, R. G., Geomagnetic storms and electric fields in the equatorial ionosphere, Nature, 268, 422-424, 1977.

Rastogi, R. G., and V. L. Patel, Effect of interplanetary magnetic field on ionosphere over the magnetic equator, Proc. Ind. Acad. Sci., 82A, 121-141, 1975.

Rastogi, R. G., and A. Patil, Complex structure of equatorial current, Curr. Sci., 55, 433-436, 1986.

Rastogi, R. G., and A. R. Patil, On certain aspects of daily variations of geomagnetic field at low latitudes, J. Geomagn. Geoelectr., 44, 495-503, 1992.

Rastogi, R. G., H. Chandra, and S. C. Chakravarty, The disappearance of Es and the reversal of electrojet current, Proc. Ind. Acad. Sci., A74, 62-67, 1971.

Rastogi, R. G., B. G. Fejer, and R. F. Woodman, Sudden disappearances of VHF radar echoes from equatorial E-region irregularities, Ind. J. Rad. Space Phys., 6, 39-43, 1977. 